Environment Conservation Journal 14(3) 47-49, 2013

ISSN 0972-3099 (Print) 2278-5124 (Online)

Abstracted and Indexed

\title{
Toxic effects of copper on the ovary of Heteropeneustes fossilis
}

\author{
Manjula Saini $₫$, Snehita Chauhan and P.K. Bajpai \\ Received: 10.01.2013 \\ Revised: 25.04 .2013 \\ Accepted: 07.5.2013
}

\begin{abstract}
Matured and acclimatized specimens of Heteropneustes fossilis were exposed to $30 \mathrm{ppm}$ cupric chloride. The fish were sacrificed on $15^{\text {th }}$ day of ovaries and were excised out. Histological preparation by the method of OFG staining was studied. Histological observations were observed that there yolk investment appeared cracked and broken due to the treatment with various reagents during paraffin impregnation. The young ova proliferated from stroma appear quite small and without a distinction of core. Most of ova were showed quite thick encapsulation. Vitellogenesis was much pronounced and delayed in liberation of ova was expected.
\end{abstract}

Keywords: Copper, Heteropneustes fossil, ovary, toxic effect

\section{Introduction}

A few years back a short collection of reports was published which include reports on pesticides metal and many more toxic agents. It is well known that industrial application and medicinal as well as other chemical over popularities of substance may spread the substance largely among population. So essential trace elements deserve to studied of their toxicological influence because it is not always very certain that in environment even such trace elements would remain as trace only. The chances are fair that a time they may rise beyond.Their harmless limits may some time raise the head of endangerment to really threatening level. Lately the books like Encyclopedia of toxicology (Wexler, 1998) running over three volumes have come and this is an example in it self that magnifies the need of studying not only lethal doses but also sub lethal doses. Davis (2000) reported slight $(<18 \%)$ decrease in $\mathrm{T} 4$ level in post menopausal women exposed to $0.68 \mathrm{mg} / \mathrm{zinc} / \mathrm{kg} / \mathrm{day}$ as zinc glucomate and did not attain statistical significance in free T3 or TSH level. Yadav and Singh (2011) observed the effect of 2,4 dichlorophenoxyacetic acid (2,4 D) on a ovary of a freshwater catfish, Heteropneustes fossilis.

\section{Author's Address}

Department of Zoology, Career College, Bhopal

Email: Manjulasaini123@gmail.com

\section{Material and methods}

Live and mature specimens of both sexes of the Heteropneustes fossilis were obtained from local fish market and put for acclimatization to the laboratory condition at room temperature for four weeks. Aquarium containing 20 litres of water was used for maintaining the fish. Prior to experiment feeding was stopped. The acclimatized fish were exposed for 15 days in 30ppm of cupric chloride after completion of the experimental exposure the fish were dissected live, wash thoroughly and were put to the dehydration. After complete dehydration the tissue sample were cleared in toluene/xylene and were process for preparation of Paraffin section cut at 6-8 micron thickness. The Paraffin section of these ovaries was stained in AF, OFG specified in Drury et al. (1976).

\section{Results and Discussion}

Copper exposed ovaries showed large inter ovum spaces and in most of the cases linear rows of ova were observed (fig.1) which possibly indicated that the ova were delayed to be set free. Thus it seems that an excess of copper might cause delay in the reproductive process. The yolk investment of the large ova observed (fig.2) crack and broken at various places but this might be an attribute to be the nature yolk that becomes harder due to the treatment of various reagents during paraffin impregnation. The young ova proliferated from the stroma and they appear quite small and without a 
distinction of the core. Therefore the copper has interfered at various stage of the development of normal ovary. However it is a matter of further investigation as to which stage is chrono biologically most sensitive to go to towards irregular growth. The different species of fish are suppose to have at least some variation in their cyclic activities therefore to rule out the variation, the widely study the species, Heteropneustes fossilis was selected as model. Seasonal changes in the gonads of common Indian cat fish, Heteropneustes fossilis was observed by Ghosh et al. (1952). It is well known that the resting phase of ovary has a thick tunica albuginea in case of copper exposure the ovaries appeared in activated but without a thickened tunica albuginea. This thin layer indicates the partial degeneration of endocrinological responses of ovary.

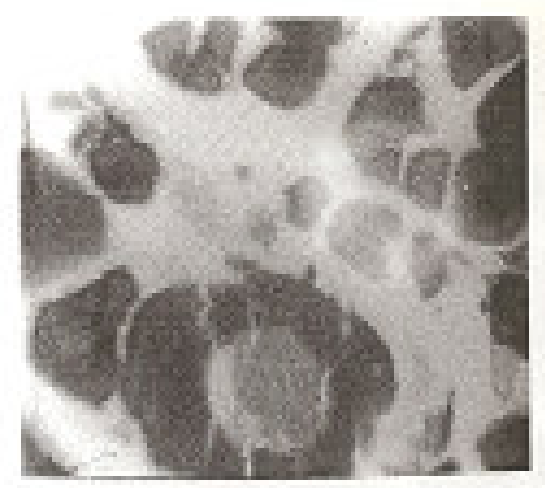

Fig.1 Photomicrograph of a part of cross-section of ovary of Hetropneustes fossilis to copper X100

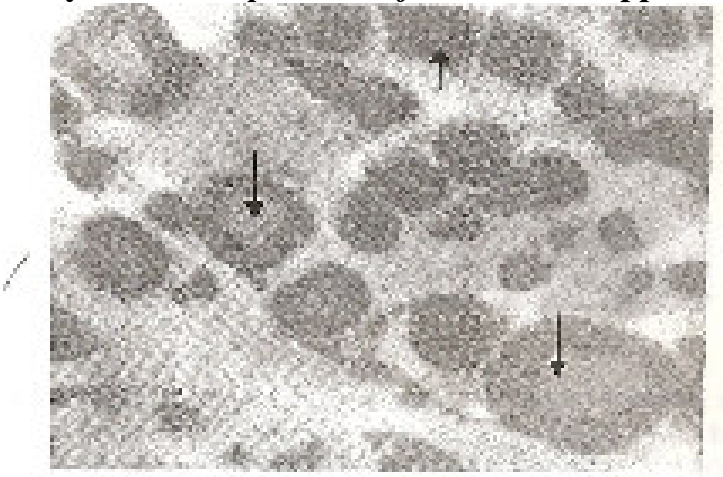

Fig. 2: Photomicrograph of a part of cross-section of ovary of Hetropneustes fossilis exposed to copper X100
The ova are distantly distributed and enclosed in columns. That indicates the failure of ovarian differentiation. The Zebra fish, Branchyclonio rario, when held in water containing $5 \mathrm{ppm}$ of zinc for a days period, the gametes were maturing showed delayed in spawning (Speranza, et al. 1977).

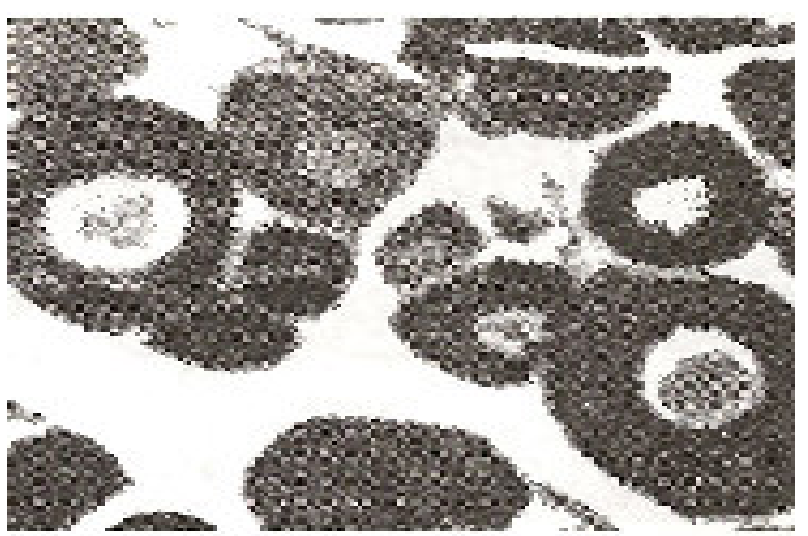

Fig.3: Photomicrograph of a part of longitudinal section of ovary of Hetropneustes fossilis X28 (Control) 38a. Mature oocytes

Copper is widely distributed in nature and is an essential heavy metal several workers Gupta et al. (1994), Stein et al. (1997) worked out that it is very toxic to fish affecting their growth as well as reproductive capacity. Ovaries are appeared in activated but without a thickened tunica albuginea ova are distantly distributed in the membranous elements in form of elongated columns. This indicated the failure of ovaries differentiation the receptor component and responses component has failed to maintain its normal behaviour and hence oogonial density and the thickness of tunica albuginea remain much less than that of normal ovary.On account of foregoing discussions it is concluded that copper is expected to be more deleterious for aquatic fauna.

\section{References}

Davis 2000. Effect of zinc glucomate on the serum level in post menopausal women. Environ. Toxicol. Chem 22 (10): $2397-2402$

Ghosh, A. and Ker, A.B. 1952. Seasonal changes in the gonads of the common Indian cat fish, Heteropneustes fossils. Proc. Zool. Soc. Bengal, 5, 29-51. 
Gupta, A.K., Sajini, C.B. and Champawat, M.S. 1994. Acute toxicity of $\mathrm{Cu}-\mathrm{Dc}-\mathrm{Pb}-\mathrm{Zn}$ to fresh water teleost, Poecilia reticulate. Proc. IIIrd Asian fish Forum, 499-502.

Speranza, A.W., Robert, J., Seeley, V.A. and Alfered, P. 1977. The effect of sublethal concentration of zinc on reproduction in the zebra fish, Branchyclonio rario (Ham) Environ, Pollut. 2 (13): 217-222.

Stein, X., Christine, R. Mauricette, G.B., Michele, R. and Mare L. 1997. Effect of copper chloride in vitro and in vivo on the hepatic EROD activity in the fish, Dicentrachus labrax. Environ. Toxicol. Chem. 16, 214-219.

Wexler, P. 1998. Encyclopedia of toxicology. Volume I, II, III Academic press, Sandiego, California.

Yadav, R.Y. and Singh, J.P.N. 2011. Effect of 2.4dichlorophenoxy acetic acid $(2,4 \mathrm{D})$ on a ovary of a freshwater catfish, Heteropneustes fossilis. J. Exp. Zool.India, 14 91) 315-318. 